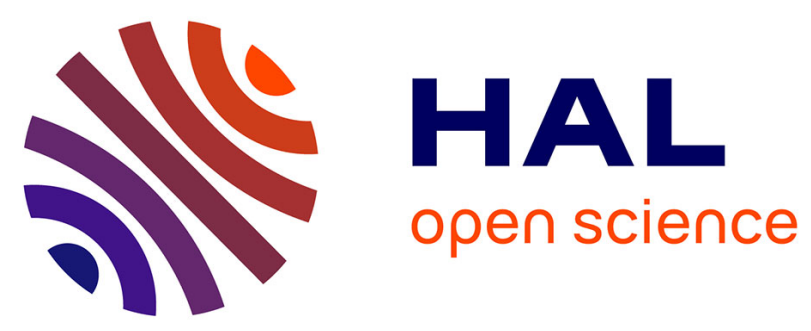

\title{
Environmental policies and eco-innovations by service firms: an agent-based model
}

\author{
Benoît Desmarchelier, Faridah Djellal, Faïz Gallouj
}

\section{To cite this version:}

Benoît Desmarchelier, Faridah Djellal, Faïz Gallouj. Environmental policies and eco-innovations by service firms: an agent-based model. Technological Forecasting and Social Change, 2013, 80 (7), pp.1395-1408. halshs-01133863

\section{HAL Id: halshs-01133863 \\ https://shs.hal.science/halshs-01133863}

Submitted on 24 Mar 2015

HAL is a multi-disciplinary open access archive for the deposit and dissemination of scientific research documents, whether they are published or not. The documents may come from teaching and research institutions in France or abroad, or from public or private research centers.
L'archive ouverte pluridisciplinaire HAL, est destinée au dépôt et à la diffusion de documents scientifiques de niveau recherche, publiés ou non, émanant des établissements d'enseignement et de recherche français ou étrangers, des laboratoires publics ou privés. 


\title{
Environmental policies and eco-innovations by service firms: an agent-based model

\author{
Benoît Desmarchelier, Faridah Djellal and Faïz Gallouj \\ University Lille 1
}

October 1, 2012

\begin{abstract}
Contrary to a widely held prejudice, service activities are polluting because they make use of physical tools and require travel, both of which give rise to externalities. In order to deal with these externalities, service firms can implement eco-innovations. The aim of this article is to evaluate the sensitivity of this eco-innovation to environmental policies by comparing the effectiveness of two such policies: the environmental tax and consumer information. To this end, we construct an agent-based model of innovation that draws on evolutionary biology and theories of innovation in services (Gallouj and Weinstein, 1997 [27]). A test of 123 different scenarios confirms that service firms are sensitive to environmental policies. The results suggest that the eco-tax is more effective, since it produces a lower and more stable level of pollution than a consumer information policy. The information policy appears to give rise to a perverse effect that causes market niches for the most environmentally friendly services to disappear.
\end{abstract}

Keywords: NK-model; cellular automata; eco-innovation in services 


\section{Introduction}

Although a number of recent studies (Gadrey, 2010 [18]; Ayres et al., 2004 [2]; Fourcroy et al., 2012 [14]) have highlighted the particularly polluting and paradoxically material nature of service economies, the environmental impact of service activities continues to be minimised. Thus, in contrast to manufacturing industry or agriculture, services are often regarded as environmentally friendly (OECD, 2000 [50]; Mannaerts, 2004 [45]; Baumol, 2010 [4]). This paradox can be explained by a failure to take proper account of the material dimension of services when greenhouse gas emissions by sector are being calculated (Gadrey, 2010 [18]; Fourcroy et al., 2012 [14]). The materiality of tangible products is, after all, regarded as the main source of negative externalities, while services are regarded as being, by definition, intangible and therefore not very polluting. This argument is mistaken, since there is in fact a fundamental association, both direct and indirect, between services and materiality. To be persuaded of this, it is sufficient simply to re-examine the traditional definition of a service (Hill, 1977 [31]; Gadrey, 1992 [17]; Gallouj, 1999 [21]). A service is a processing operation carried out by a service provider at the request of a customer and intended to bring about a change of state in a medium. This medium may be a material object, codified information, an individual or knowledge. The customer frequently participates in the processing operation, as part of a co-production relationship. A definition of this kind brings to light various sources of materiality: the medium, the tools and goods (including real estate) used to provide the service and the coproduction relationship itself, which may require the customer and/or service provider and/or the medium to travel or be transported.

Services' contribution to employment and the creation of value added in contemporary economies, as well as the negative environmental impact of these activities, means that the question of eco-innovation in and by services should be regarded as a major concern. However, the treatment of environmental problems is often characterised by a 'sectoral and technologist bias' (Djellal and Gallouj, 2009 [11]) that causes non-technological eco-innovations in manufacturing and agriculture and eco-innovations in the service sector (whether technological or not) to be ignored. Thus not a single service activity is included in the activities investigated in a recent European Commission report on eco-innovations (European Commission, 2009 [12]) and only technological innovations are discussed.

According to Gallouj (1994 [20]) (see also Gallouj and Weinstein, 1997 [27]; Gallouj and Savona, 2009 [25]; Gallouj 2010 [24]), the question of innovation in services can be approached from three different theoretical perspectives: assimilation, differentiation and integration. All three approaches can be applied to the problem of eco-innovation in services (Djellal and Gallouj, 2009 [11]). In the assimilation approach, innovation in services is regarded as resulting from the adoption of technological innovations produced in other sectors. From this perspective, therefore, eco-innovation in services consists quite simply of the adoption of more environmentally friendly technologies (e.g. new types of heating, electric vehicles, etc.). The differentiation approach, for its 
part, emphasises the importance of non-technological forms of innovation in services. In this framework, eco-innovations are non-technological advances that reduce a service's environmental impact (eco-tourism, savings accounts associated with sustainable development programmes, use of local products in restaurants, etc.). The integration approach (Gallouj and Weinstein, 1997 $[27]$ ), which takes as its starting point the observation that manufacturing and industry are converging to some extent, uses the same tools to analyse innovation processes and their results in both manufacturing and service activities. This approach is based on the decomposition of the product (good or service) into vectors of characteristics, following the tradition established by Lancaster $(1966[43])^{1}$. An innovation is produced when a product's internal or external vectors of characteristics are modified. From this integrationist perspective, an example of eco-innovation is the development by manufacturing companies of strategies for leasing their products. In this case, the good in question is no longer regarded as a material artefact but rather as a package of service functions or characteristics.

The question we wish to investigate in this paper is not whether or not eco-innovation exists in services. The examples that have just been mentioned, to which many others could be added, are sufficient to establish the idea that services themselves can produce eco-innovation. Rather we are concerned here with public policies. We are seeking to verify the extent to which service firms' eco-innovation is sensitive to public policies on protecting the environment and to compare different types of public policies in terms of their ability to foster eco-innovation in services.

The objective of this paper is to provide a theoretical response to these two questions by constructing an agent-based model of eco-innovation in services. More precisely, the aim is, on the one hand, to investigate the extent to which environmental tax policies and consumer information policies are able to foster eco-innovation in services and, on the other, to assess which of these policies is the more effective in terms of its ability to bring about the creation of a more or less environmentally friendly dominant design. It should be noted that, in the light of the above-mentioned trend to convergence between services and manufacturing industry, we are proposing a model based on the integrationist approach to innovation. The article is divided into three sections. In the first part, we lay the theoretical foundations for a model of eco-innovation in service firms. In the second part, we construct the model that arises from these foundations and outline its properties. In order to take account of the specificities of services, the model incorporates the two main channels through which service activities pollute: their material nature and their interactivity (co-production), which may give rise to travel. In the third part, we present and discuss the results of our simulations of the influence of fiscal and consumer information policies on eco-innovation in service firms.

\footnotetext{
${ }^{1}$ For applications on the field of innovation in services, see Gallouj and Weinstein, 1997 [27]; Saviotti and Metcalfe, 1984 [53]; de Vries, 2006 [10]; Windrum and Garcia-Goñi 2008 [55]
} 


\section{Theoretical framework}

The amount of literature on innovation in services is steadily increasing, shifting (as reminded in the introduction) from assimilation to differentiation and finally integration perspectives. The integrative approach which we favour in this paper is built on the Lancasterian conception of the product (goods or services), conceived as a set of technical and services characteristics (Lancaster, 1966 [43]). In such a characteristics-based approach (Saviotti and Metcalfe, 1984 [53], Gallouj and Weinstein, 1997 [27]), a product can be broken down into three broad categories of service characteristics ${ }^{2}$ :

- the principal characteristics, that is those that motivate purchase of the product in the first place;

- the complementary characteristics, which determine the performance of the principal characteristics;

- the externalities, which are characteristics that are not desired.

According to the above mentioned definition of service activities, we will single out two types of negative externalities linked to the two sources of pollution identified previously: those arising out of the mobility caused by the interactive nature of services and those arising out of the material environment in which services are provided.

It follows that the environmental problem of a service firm can be regarded as a choice of the "best" vector of final characteristics. From this point of view, three important characteristics can be identified: the price $^{3}$ of the service, the externalities it generates and the requirement for consumers to travel ${ }^{4}$. The externalities include the two sources listed above, namely those linked to mobility (in this case, mobility on the part of the customer, service provider and service medium) and those linked to the service's materiality. The introduction of consumer mobility as a characteristic is justified by the fact that consumers may be sensitive to the mobility constraints (prefer mobility) regardless of the question of pollution. The vector of the service characteristics is given by equation 1 .

$$
\left(\begin{array}{c}
x_{k t} \\
y_{k t}=f\left(m_{k t}\right)+v_{k t} \\
z_{k t}
\end{array}\right)
$$

$x_{k t}$ is the price of the service provided by firm $k$ at time $t, y_{k t}$ represents the externalities generated by the service. $y_{k t}$ is the sum of the externalities linked to mobility, $f\left(m_{k t}\right)$, and of the externalities linked to materiality $v_{k t}$. $m_{k t}$ represents the total mobility associated with the service transaction: mobility of the customer, service provider and service medium. $z_{k t}$ is

\footnotetext{
${ }^{2} \mathrm{~A}$ service or final characteristic is a characteristic that gives utility to customer.

${ }^{3}$ Price is not a service characteristic as defined by Saviotti and Metcalfe (1984 [53]) since it does not in itself provide utility. However, it is an essential lever that can be activated by the public authorities in order to encourage the diffusion of environmental products.

${ }^{4}$ Since the vector of characteristics we are creating is evaluated by the customer, the mobility of the service provider and of the service medium is not included in this dimension of mobility.
} 
the mobility required of the customer in order to consume the service provided by firm $k$ such as $z_{k t} \leq m_{k t}$. The conversion of this mobility $m_{k t}{ }^{5}$ into an externality is operated by the function $f($.$) , which is a standardisation$ of $m_{k t}$. In the light of existing production technologies and habits, we define a minimum level of mobility, $m_{\min }$ and a maximum level $m_{\max }$, such as $f\left(m_{k t}\right)=10 \times\left(m_{k t}-m_{\min }\right) /\left(m_{\max }-m_{\min }\right)$.

In the framework we build, the service firm faces the problem of choosing its service design: it must choose its vector $\left(\begin{array}{lll}x_{k t} & y_{k t} & z_{k t}\end{array}\right)$. This problem is similar to that formalised by biological models of adaptation (Holland, 1992 [33]), also known as 'search models' (Chang and Harrington, 2006 [9]). The aim of the following section is to outline the origin and principles of these models, as well as their main applications in economics.

\subsection{Models of adaptation: from evolutionary biol- ogy to evolutionary economics}

Models of adaptation were first used as a tool in the investigation of selection and mutation mechanisms in living organisms over a long period but can also be applied in many other areas (Holland, 1992 [33]). The purpose of this section is briefly to outline the underlying principles of these models, with a particular emphasis on the NK model, which is the one most frequently used in economics. We will also identify the model's limitations when applied to economics.

Kauffman (1993 [38]; 1995 [39]) draws on Wright (1931 [57]) in an attempt to simulate the evolution of a population of artificial organisms in an $\mathrm{N}$-dimensional space. Each of these dimensions represents a particular gene made up of two alleles. These alleles are symbolised by a binary chain and thus each gene, or dimension, may be in one of two states: 0 or 1 . Furthermore, each gene is assumed to be covariant with $K$ other genes, selected at random. In order to direct the organisms' search, a performance value (fitness) is attributed to each of the loci in the $\mathrm{N}$-dimensional space. In practical terms, this value is obtained by calculating for each locus the average of $2^{k+1}$ draws according to a law of probability. Thus the model's search environment is wholly defined by the two parameters $N$ and $K$, which explains its name.

The fitness surface thus obtained is very often 'rugged' and at the same time more or less covariant (Kauffman, 1995 [39]). Consequently, it comprises many local extremes without for all that being totally random. Figure 1 represents the two extreme cases of a covariant surface and a random surface, both of them defined around a two-dimensional space. In biology, the goal of organisms evolving on such surfaces is to find the global optimum or a locus that comes close to it. In order to achieve this goal, organisms undergo a process of local adaptation through incremental mutations, although there are also possibilities for more substantial mutations by means of 'jumps' across

\footnotetext{
${ }^{5}$ More precisely, $m_{k t}$ is the product of a random draw according to a uniform law defined around the interval $\left[z_{k t} ; 10\right]$
} 
the surface.

The $N K$ model has been used in various ways in the economics literature. Thus March (1991 [46]) shows the positive effect for firms of having employees who are quickly socialised and have a fairly high turnover when their cognitive environment, represented by a random fitness surface, is shifting. For his part, Levinthal (1997 [44]) shows that it is long-distance search strategies that enable firms to survive sudden changes in their environment. By making movement across a surface costly for firms, Kauffman, Lobo and Macready (2000 [40]) attempt to determine the optimal search distance for firms. According to their analyses, a rational firm will begin with a long-distance search (radical innovation) and then, as its performance improves, it will adopt a local search (incremental innovation).

These various applications of the NK model in economics have the merit of highlighting the wide diversity of economic problems to which adaptation models can be applied. However, this biological model has certain weaknesses when applied to economics. It is, after all, based on a random fitness surface which has no economic foundation (Chang and Harrington, 2006 [9]). Furthermore, since the simulated search processes correspond in fact to innovation processes, these applications can be criticised for not taking account of the economic environment in which firms' searches take place. These models do not consider the multiple and constant interactions between the spheres of research, innovation, production, diffusion and consumption (Kline and Rosenberg, 1986 [42]).

The adaptation model put forward by Chang and Harrington (2000 [7]; $2004[8] ; 2006$ [9]) is undeniably an attempt to anchor the construction of the performance surface in economic theory. This model attempts to establish what the optimal degree of centralisation is for the organisation of a large retail firm made up of a parent company and several subsidiaries. Each of the subsidiaries operates in its own market and therefore has to deal with its own specific optimisation problem. In concrete terms, a subsidiary $j$ evolves in a space with $N$ activities, each one made up of $R$ commercial practices ${ }^{6}$. Thus the adaptation space is of size $R^{N}$ and the firm seeks the combination of practices that maximises the performance surface, which is calculated as a profit surface. The demand function used by the authors for each individual consumer $i$ is based on the implicit assumption that, whatever the vector practices chosen by the firm is, a strictly positive quantity of its product will be purchased by every consumer in the market. After the sum of the quantities demanded by consumers for each locus in $R^{N}$ has been calculated, a profit surface is defined in that space. The challenge for the firm is to maximise this surface.

The value added of Chang and Harrington's model (Chang and Harrington (2000 [7], 2004 [8], 2006 [9]), compared to previous $N K$ models, is that it

\footnotetext{
${ }^{6 "}$ These practices represent all of those elements that influence the appeal of this store to consumers. It can include the types of products carried [...] the number of products carried [...] and compensation schemes" (Chang and Harrington, 2000 [7], p. 1429).
} 
provides an explicitly economic foundation for the fitness surface, in particular by introducing an interaction between consumer preferences and a firm's search heuristic. However, this interaction is not completely consistent with the non-linear perspective on the innovation process (Kline and Rosenberg, 1986 [42]), since consumer preferences are static in Chang and Harrington. Furthermore, consumers of their model demand a positive quantity of products regardless of the firm's practices vector, which suggests that this model is only suitable for monopoly situations. After all, if several firms were active in this market, each consumer would purchase a positive quantity of products from each firm operating in the market. These observations suggest that great importance should be attached to consumer theory in the construction of such an adaption model in economics.

\subsection{Interpersonal influences and the dynamics of opinion formation}

Evolutionary theories of the consumer pay particular attention to the dynamics of preferences. Despite the great diversity of theories put forward, there exist a consensus around the notion of social network for explaining these dynamics (Witt, 2001[56]; Janssen and Jager, 2001 [36]; 2002 [37]; Cantono and Silverberg, 2009 [5]; Nelson and Consoli, 2010 [49]). In this view, consumers evolve in a multi-agent universe and their preferences are influenced by those of their neighbours or of the individuals with whom they interact. This concept of the individual as an entity susceptible to influence is (1) compatible with Rogers' (1995 [52]) theory of innovation diffusion, (2) often formalised by a cellular automaton and (3) can be combined with the social psychological theory of the dynamics of opinion formation (French, 1956 [15]; Friedkin, 1986 [16]; Hegselmann and Krause, 2002 [29] et 2005 [30]). These three points are examined in greater detail in this subsection.

Rogers (1995 [52]) sets out to explain the well-established stylised fact that, if a product is successfully diffused, then its market share and number of units sold follow an S-shaped temporal trajectory. According to Rogers, such a trajectory can be explained by the following three characteristics: (1) individuals are heterogeneous, particularly in terms of preferences and their aptitude to accept novelty $^{7},(2)$ they are susceptible to influence and (3) most of them are characterised by homophily, that is they tend to associate with individuals to whom they are relatively similar in terms of tastes, social status, opinions etc. Thus the global consumer network has to be considered as an aggregate of many different sub-networks, each made up of similar individuals. In the extreme case in which all individuals are characterised by homophily, the various sub-networks are independent of each other, which may make diffusion of an innovation difficult. On the other hand, when a certain number of heterophile agents are present in the population, they can act as 'bridges' between the sub-networks and become opinion leaders by influencing the members of many

${ }^{7}$ Thus Rogers (1995[52]) proposes breaking the consumer population down into five categories, ranked in descending order of openness to novelty: innovators, early adopters, early majority, late majority and laggards. 
other sub-networks in their decisions on whether or not to adopt an innovation. When a critical mass of individuals has been persuaded, a self-sustaining dynamic of innovation diffusion becomes established. Thus the diffusion of an innovation depends on a certain balance between heterophily and homophily among consumers.

This theory seems to be entirely compatible with attempts to produce an evolutionary theory of the consumer. According to Witt (2001 [56]), the satisfaction of human needs often requires the use of tools that are assumed by human beings to be able to satisfy the need they are experiencing. Thus consumers acquire what is called "consumption knowledge [...] by communicating with, and observing and imitating, other consumers" (p. 28). This same idea of influence is also found in the theory of the consumer developed by Nelson and Consoli (2010 [49]). For these authors, individual preferences are never truly in balance, since they are influenced by many factors, including 'friends', i.e. individuals' social networks, as well as age, accidents etc.

A common way of representing agents whose preferences and choices are constantly changing under the influence of a social network is to use a twodimensional cellular automaton (Hegselmann and Flache, 1998 [28]; Hegselmann and Krause, 2002 [29] and 2005 [30]; Janssen and Jager, 1999 [35]; Cantono and Silverberg, 2009 [5]), that is a matrix in which each cell can take on different states. In the present case, each cell represents a consumer whose possible states are individual preferences. A consumer's state is constantly influenced by the states of the other consumers within a given neighbourhood, such that the cellular automaton is constantly in motion. Thus a cellular automaton can perfectly represent both the idea of an absence of equilibrium found in Nelson and Consoli (2010 [49]) and that of individual embeddedness in influence networks (Rogers, 1995 [52]; Witt, 2001 [56]).

A theory of the evolution of consumer preferences that can be used in a cellular automaton is to be found in studies of the influence of social interactions on individuals' opinions. Following the work of French (1956 [15]), a number of authors, including Friedkin (1986 [16]) and Hegselmann and Krause (2002 [29] and 2005 [30]), have proposed representing an individual's opinion by the average of his opinion and that of his neighbourhood. This method has the advantage of being very flexible, since averages can be calculated in a number of different ways, just as the weighting coefficients used can be fixed or dynamic. In general terms, assuming that an individual $i$ has $j=n$ influential neighbours, and if $x_{i t}$ is the opinion of the individual $i$ at time $t$ and $a_{i j}$ the importance attached by $i$ to the opinion of his neighbour $j$, we have:

$$
x_{i t}=\sum_{j=1}^{j=n} a_{i j} \cdot x_{j t-1}
$$

with $a_{i j}$ such as $\sum_{j=1}^{j=n} a_{i j}=1$.

It can be demonstrated that equation (3), which represents the evolution of individual preferences, leads to consensus from the point at which each pair of agents positively weights the opinion of a third agent (Hegselmann and Krause, 
2002 [29]). We propose to adopt this equation to represent the dynamic of consumers' opinions in the model to be constructed in the second part of this article.

\section{Building of the agent-based model}

In this second part, our objective is to construct an agent-based model of ecoinnovation in services that is consistent with the hypotheses discussed above (consumer behaviour and definition of the search space). The model will be constructed in two stages ${ }^{8}$. We begin by presenting the search space and the associated fitness landscape. We then formulate our hypotheses about service firms' adaptive capabilities in that space.

\subsection{Search space and performance measure}

The dimensions of the search space are those of the product presented in equation (1). Thus a firm $k$ will offer a service at price $x_{k t}$, with externality ${ }^{9} y_{k t}$ and requiring customer mobility $z_{k t}$. Adaptation (or search) models are discrete optimisation models. Hence each dimension in the space to be optimised is defined by a finite whole number of variants. By convention, each of our three dimensions will comprise 10 variants such as $x_{k t} \in[1 ; 10], y_{k t} \in[1 ; 10]$ and $^{10} z_{k t} \in[1 ; 10]$. Thus the adaptation space offer $10^{3}$ possible loci or service designs. The values assigned to each locus can be used to classify and compare the corresponding designs. Thus the design corresponding to locus $\left(\begin{array}{lll}5 & 3 & 2\end{array}\right)$ is more expensive, less polluting and requires less customer mobility than design ( $\left.\begin{array}{lll}4 & 6 & 4\end{array}\right)$.

As in all adaptation models, a performance value is attributed to each of the loci in the space. The particularity of our model is that this value depends on consumer preferences. The model comprises 400 consumers represented by a cellular automaton of size $20 \times 20$. At the beginning of the simulation, a vector of initial preferences $\left(\begin{array}{lll}x_{i t} & y_{i t} & z_{i t}\end{array}\right)$ is attributed to each consumer $i$. If $R N D(1 ; 10)$ denotes a random draw according to a uniform law defined in the discrete interval $[1 ; 10]$, the initial preferences are attributed by the following procedure.

$$
\begin{gathered}
x_{i}=\operatorname{RND}(1 ; 10) \\
\text { if } \mathrm{x}_{i}>5 \text { then }\left(\begin{array}{c}
y_{i} \\
z_{i}
\end{array}\right)=\left(\begin{array}{l}
R N D(1 ; 5) \\
R N D(1 ; 5)
\end{array}\right)
\end{gathered}
$$

\footnotetext{
${ }^{8}$ The code of the model has been written on the Marco Valente's Laboratory for Simulation Development software. This software is freely downloadable at the following address: http : //www.labsimdev.org/Joomla $a_{1}-3 /$

${ }^{9}$ It will be remembered that there are two types of externalities: those produced by mobility $f\left(m_{k t}\right)$ and those produced by materiality $v_{k t}$, such that $y_{k t}=f\left(m_{k t}\right)+v_{k t}$.

${ }^{10}$ In certain cases, we will have $y_{k t} \in[2 ; 20]$. This point will be discussed later in the paper.
} 


$$
\text { if } \mathrm{x}_{i} \leq 5 \text { then }\left(\begin{array}{c}
y_{i} \\
z_{i}
\end{array}\right)=\left(\begin{array}{l}
R N D(6 ; 10) \\
R N D(6 ; 10)
\end{array}\right)
$$

In other words, it is being assumed that those consumers who are prepared to pay the highest prices are also more concerned with the environmental quality and proximity of the service they are purchasing. Furthermore, each consumer can purchase only one service per time period and he will buy the one that obtains him the greatest utility, i.e. the one closest to his own vector of preferences. In what follows, we will be testing various scenarios: if agents take into account just one source of externality, we will have $y_{i} \in[1 ; 10]$ and $y_{k} \in[1 ; 10]$. If, on the other hand, the two sources are taken into account, we will have $y_{i} \in[2 ; 20]$ et $y_{k} \in[2 ; 20]$. In the absence of an environmental policy, however, our consumers ignore the characteristic $y$.

The preferences dynamics of a consumer $i$ depends on the preferences of his neighbours $j$. The influential neighbourhood is a Von Neumann type of neighbourhood, such that the neighbours $j$ that influence $i$ are those that will be located immediately above, below, to the right and to the left of $i$ (cf. figure 2). The preferences dynamics of $i$ are given by equation 3 .

$$
\left(\begin{array}{l}
x_{i t} \\
y_{i t} \\
z_{i t}
\end{array}\right)=\left(\begin{array}{c}
\beta_{i} x_{i t-1}+\left(1-\beta_{i}\right) \cdot(1 / n) \sum_{j} x_{j t-1} \\
\beta_{i} y_{i t-1}+\left(1-\beta_{i}\right) \cdot(1 / n) \sum_{j} y_{j t-1} \\
\beta_{i} z_{i t-1}+\left(1-\beta_{i}\right) \cdot(1 / n) \sum_{j} z_{j t-1}
\end{array}\right)
$$

With $\beta_{i} \in(0.1 ; 0.9)$, a parameter indicating consumer $i$ 's independence from his neighbours ${ }^{11}$ and $n$, the number of influential neighbours. In the standard case, $n=4$ but we shall see that this value can change depending on the scenario under consideration. The performance value $U_{l t}$ of locus $l$ in $t$ is given by equation 4 .

$$
U_{l t}=\left(\frac{1}{N}\right) \sum_{i=1}^{N}\left[10-\frac{1}{3} \cdot\left(\left|x_{i t-1}-x_{l}\right|+\left|y_{i t-1}-y_{l}\right|+\left|z_{i t-1}-z_{l}\right|\right)\right]
$$

With $\left(\begin{array}{lll}x_{l} & y_{l} & z_{l}\end{array}\right)$ the coordinates of the locus (or design) $l$ in the threedimensional search space and $N=400$, the total number of consumers. This equation means that the closer a design $l$ is to the preference vector of a large number of consumers, the better this design's performance is from the firms' point of view, thereby increasing its attractiveness to them. Moreover, $U_{l t} \in[1 ; 10]$ since each distance $\left|x_{i t-1}-x_{l}\right|$ is at least equal to 0 and at most equal to 9 .

To sum up, consumer preferences evolve as is clear from equation 3, which gives rise to variations in the performance values of loci in firms' search space (equation 4). The model could be thought to represent a market in which consumers are polled in each period. The results of the poll show firms the more or less environmentally friendly design they should strive for. The model's functioning is summarised by figure 3 .

${ }^{11}$ The parameter $\beta_{i}$ of each consumer is chosen at random at the begining of a simulation run. 


\subsection{Firms' search heuristic and its relevance for ser- vice sectors}

Innovation in services was long neglected in the economic literature. When it did finally attract interest from researchers, it was initially concluded that services suffered from a certain weakness in this area. They were said to be not very innovative: after all, they produce little in the way of technological innovation and do not rely on $R \& D$ activities (which would be the responsibility of specialist R\&D departments). A number of relatively recent studies (Gallouj, 2002 [22]; Miles, 2002 [47]; Gadrey and Gallouj, 2002 [19]; Tether, 2005 [54], Howells, 2007 [34], Hipp and Grupp 2005 [32]; for a recent summary, cf. Gallouj and Djellal, 2010 [23]) have called these negative judgements into question. These authors demonstrate that there are hidden innovations in service that cannot be captured by the traditional analytical tools (non-technological product and process innovations, ad-hoc and tailor-made innovations, organisational innovations, social innovations, etc. $)^{12}$. Following this literature, we suppose that service firms of the model are conducting research activities (even if it is non-technological research) at each time step.

Firms of the model are rational in the sense that they seek to maximize the fitness of the product they offer on the market. However,this rationality is exercised in a context of limited information: firms do not know what is the best product design in terms of fitness. The model includes 10 businesses $k$, whose initial position in $t=0$ is attributed at random. Kauffman (1995 [39]) proposes a performant search heuristic which produces relevant economic results (learning curves and radical innovations followed by incremental innovations). We adopt therefore his heuristic : firms of the model have a local knowledge of their environment, while having the ability to make long jumps in order to explore unknown areas (see heuristic on table 1).

$M S_{k t}$ and $\bar{M} S_{t}$ represent respectively the market share of the firm $k$ and the average market share of the current period. Adopting this heuristic, we consider that there is no incentive to innovate for a firm whose market share is larger than the average. This assumption reflects the idea that the result of an innovation in terms of market share is uncertain. Indeed, all firms seek the same design, that is the one who has the highest fitness value. If they all find this design, the market share a firm $k$ can expect is $\bar{M} S_{t}$. Thus, it may be advantageous for a firm $k$ to hold on a position, considered as sub-optimal from the point of view of its overall fitness, as it ensures $M S_{k t}>\bar{M} S_{t}$. We say in this case that the firm exploits a niche market.

For the entries and exits of firms, we assume a constant population. A

\footnotetext{
${ }^{12}$ The taxonomic approach of innovation in services illustrates the heterogeneity of innovation trajectories between different service sectors (Evangelista, 2000 [13]; Castellacci, 2008 [6]). It is possible to address this issue with our model. But for that purpose, the dimensions of the service characteristics space, their interrelationships, as well as the construction of the fitness landscape upon it, should be adapted to each specific sector. This is an interesting avenue for future research. For now, we can only consider that the model addresses the specific problem of product eco-innovation faced by consumer service firms.
} 
firm is removed from the model once it meets a null market share. It is therefore immediately replaced by a new entrant, which can be an innovator or an imitator. We use the Herfindahl-Hirschman Index (HHI) for deciding whether market entries are innovative or replicative. Concretely, a random draw on a uniform distribution $R N D(0 ; 1)$ is performed at each new entry. If $R N D(0 ; 1)>H H I$, then the entrant is an innovator. Thus, the more the market is close to a monopoly the more the likelihood is important of an imitative entry. The imitator copies the best design among the existing firms. The incoming innovator chooses for his part 5 designs randomly among the $10^{3}$ possibilities offered by the model, he compares their fitness value with the one of the dominant firm and chooses the design which offers the highest fitness. There will therefore be less and less innovative firms as the market matures, and thus as the incumbents approach the best possible fitness value. The model incorporates therefore a locking mechanism of the product design proposed by firms. This locking is the product of an overlapping between limited "technological possibilities" for product designs and limited demand for new product designs.

Some of the emerging dynamics of the model are reproduced in figures 4 and 5. We observe that they are consistent with the theory of the Product Life cycle (Abernathy et al., 1983 [1]; Kleper, 1996 [41]). At the beginning of a simulation, consumer preferences are very heterogenous, which creates a strong uncertainty on the viability of the various possibilities of product design. This uncertainty, characterized by a rather rugged fitness landscape, pushes on the typical firm to undertake some radical innovations in order to differentiate itself from its competitors. The resulting wave of radical innovations produces the rapid growth of the fitness of all the firms at the very beginning of the simulation on figure 4. However, the progressive homogeneization of consumer preferences (cf. equation 3 ) gives rise to a limited number of standards (figure 5) involving the virtual absence of radical and product innovations when the sector reaches its maturity. Abernathy et al. (1983 [1]) sum up the link between the product life cycle and the sector life cycle by the following conclusion: "maturity (...) is the process by which competition becomes progressively immune to technology-based change from within the industry" (p. 27).

The model seems then consistent with the evolution of products in industrial sectors, but what about the evolution in service sectors ? Barras (1986 [3]) argues the existence of a reverse product cycle in services. To our knowledge, this phenomenon has been observed only in a limited number of "supplier dominated" (Pavitt, 1984 [51]) service sectors like insurance, accountancy and local governments. Moreover, the increasing convergence between industry and services (the industrialization of services and the servitization of goods) requires to qualify the idea of specificities of innovation in services. As far as the theory of product life cycle is concerned, Abernathy et al. (1983 [1]) recognizes that, contrary to what is observed in biological world, there is always possibilities of reversal in the economic world. As a consequence, we do not consider the reverse product cycle as a specificity of services. Such a reversal can be led by major changes in demand conditions, and we consider that producing such a change has to be one of the main objective of any 
environmental policies.

\section{Environmental policies and green prod- uct innovations in services}

Our purpose is to use the agent-based model in order to answer our two initial questions: do environmental policies have an effect on the environmental design of the services offered in the market? If the need arises, which is the more effective of the two policies: taxing externalities or informing consumers? Since our model offers numerous possible environmental policy scenarios, we begin by outlining all the scenarios that were tested before going on to present the results.

\subsection{Environmental policies}

By definition, an external effect is not evaluated by the market. Thus when no environmental policy is applied, consumers' behaviour is determined by the following two hypotheses:

1. consumer tolerance $y_{i t}$ for the externalities is fixed,

2. the externalities do not influence purchasing decisions.

Consequently, in the absence of any public policy, the performance value of the various designs and the evolution thereof are totally independent of the 'externality' dimension of the service. Environmental policies may be brought to bear on all the externalities $y_{k t}$ or on some of their components: just those externalities linked to mobility $f\left(m_{k t}\right)$ or the degradations caused by the material nature of the service $v_{k t}$. If $m s_{k t}$ denotes the market share of the firm $k$ in $t$,we calculate an average pollution index $\bar{y}_{t}$. This index takes account of the total externalities $y_{k t}$ since even if the agents are not aware of it, it is still the level of pollution $y_{k t}$ that is released into the environment when each service transaction is concluded.

$$
\bar{y}_{t}=\sum_{k=1}^{10} m s_{k t} . y_{k t}
$$

It is this indicator that will be used to evaluate the effect of public policies. Two types of environmental policies are considered in our simulations: an ecotax and a consumer information policy, implemented by means of labels, for example.

\subsubsection{The eco-tax}

In application of the 'polluter pays' principle, the tax to be paid by a firm $k$ consists of a sum $T$ equal to the level of externality detected and measured by the public authorities. Three scenarios are possible: $T=f\left(m_{k t}\right), T=v_{k t}$ or $T=y_{k t}=f\left(m_{k t}\right)+v_{k t}$. The immediate effect of the tax will be to alter the price scale (table 2), without consumers' ability to pay being affected, which ought to force firms to adopt more environmentally friendly designs. 


\subsubsection{The information policy}

At the beginning of the simulation, the externalities $y_{k t}$ that are produced are not evaluated by consumers and their environmental preferences $y_{i t}$ are inactive. The information policies are a means of correcting this lack of clearsightedness on the part of the agents. As with taxation, three situations are possible: the information may relate to one of the two sources of externality, $f\left(m_{k t}\right)$ or $v_{k t}$, or to both at the same time, $y_{k t}$.

The consumers are heterogeneous (their preferences $y_{i t}$ are different). We assume, therefore, that an information campaign will have two different effects occurring at different times.

- An immediate effect: the most environmentally aware consumers react immediately by taking account of the externality identified by the public authorities $\left(f\left(m_{k t}\right), v_{k t}\right.$ or $y_{k t}$ as the case may be) in their purchasing decisions. In order to represent this effect, we define a threshold $E$ such that, if individual $i$ 's tolerance $y_{i t}$ for the externalities fulfils the condition $y_{i t} \leq E$, then individual $i$ will take account of information that he has received in his purchasing decision. Furthermore, the preference $y_{i t}$ will subsequently be influenced by the environmental preferences of other environmentally aware consumers located in his neighbourhood (on condition that such consumers are indeed to be found in this neighbourhood).

- A mediate effect: the consumers $j$ whose preferences are such that $y_{j t}>E$ may also become environmentally aware by being influenced by their neighbours. If $K$ denotes a parameter indicating the number of environmentally aware neighbours $\left(n_{e t}\right)$ necessary to trigger a process of contagion, $j$ will also adopt an environmentally aware attitude as soon as $n_{e t} \geq K$.

\subsection{Results}

Each simulation lasts for 500 periods and the environmental policies are put in place from period 200 onwards. The parameters $E$ and $K$ offer a great variety of simulation possibilities. Thus for each level of information held by the public authorities on the externalities (whether it be that linked to mobility $f\left(m_{k t}\right)$, to materiality $v_{k t}$, or both together $\left.y_{k t}\right)$, we simulated all the scenarios described in Table 3.

We thus considered 123 scenarios. Each of them has been repeated 20 times. For each scenario, the average of the global pollution index $\bar{y}_{t}$ for these repetitions is plotted in the figures 6 to 9 . In order to facilitate the interpretation of these figures, we distinguish two different groups of scenarios: (1) the situations where the diffusion of behaviors is difficult among the consumers ( $E \leq 5 \& K \geq 2$, see the red dashed curves on the figures), (2) the situations where this behavioral diffusion is relatively easy (all the other cases, represented by solid curves). 


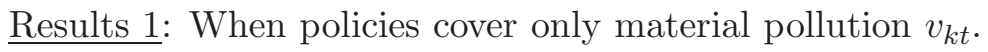

These results are reported in figure 6. The comparison of parts (a) and (b) reveals that the use of an ecotax permits to reach a lower overall level of externalities $\bar{y}_{t}$ than the implementation of only a consumer information policy. We also observe, on the two parts of the figure, that the scenarios with a weak diffusion of behaviors amongst consumers $(E \leq 5 \& K \geq 2$, red dashed curves) reach the lowest levels of externalities. But in these latter cases, the standard deviation of $\bar{y}_{t}$ seems to be particularly high, especially in the part (b) of the figure, that is without the ecotax.

These two results (a greater efficacy of the ecotax and an important standard deviation when $E \leq 5 \& K \geq 2$ ) can be explained by equation 3 describing the evolution of consumer preferences. This equation contributes to a homogeneization and an averaging of consumer preferences. Consequently, when the diffusion of new behaviors is difficult, consumers remain heterogenous and at least two dominant designs coexist in terms of externalities: one is environment friendly and the other is a rather pollutant design, which explains the high standard deviation of $\bar{y}_{t}$. On the opposite, when behavioral diffusion is easy, the rather poor ecological performance is due to the fact that more and more environment-sceptical consumers enter the public debate. The feedback of their preferences on the preferences of the ecological consumers renders these latter progressively less sensible to the environment. In other words, our simulations tell us that it can be better for the environment to face a bipolar population of consumers because it creates niche markets for the most environment friendly products.

The ecotax helps, for its part, to ensure the emergence of an environment friendly dominant design. Indeed, such a policy renders less costly the more ecological products. This satisfies both the ecological consumers and the others who search before all the cheapest products.

$\underline{\text { Results 2: }}$ When policies cover only pollution coming from mobility $f\left(m_{k t}\right)$.

Figure 7 presents the results of simulations conducted under the assumption of an ecotax and / or of a consumer information about externalities $f\left(m_{k t}\right)$ related to the mobility of the product.

We observe that the addition of an ecotax still reduces the standard deviation of $\bar{y}_{t}$, and that it always manages to bring out a rather dominant ecological design. Part (b) of the figure shows that the cognitive characteristics of the population have, once again, an important role in the success of an information policy. But unlike the previous case, where this policy covered $v_{k t}$, we observe here that the difficult diffusion of behaviors, $E \leq 5 \& K \geq 2$, produces the worst results. We explain this opposite relationship by the preexisting lock-in of consumers in a product design in terms of client mobility $z_{k t}$. Indeed, since by assumption $m_{k t} \geq z_{k t}$, possibilities for ecological designs in terms of mobility are reduced for firms. In this situation, it is better for the environment to face a population of homogeneous "average" consumers rather 
than to face an heterogeneous population where it would not be technically feasible to satisfy the more ecological preferences.

(a) of the figure shows that adding an eco-tax is a good way to limit the impact of cognitive characteristics of consumers in the average level of externalities $\bar{y}_{t}$. Indeed, with such a policy the distinction of the results between the cases where the diffusion of behaviors among consumers is easy and the cases where it is difficult appears to be less relevant.

Results 3: When policies cover all the sources of externalities $y_{k t}=v_{k t}+$ $f\left(m_{k t}\right)$.

As we could expect, this scenario (Figure 8) achieves lower levels of externalities than the previous two cases. Overall, the ecotax still reduces the standard deviation of $\bar{y}_{t}$, but the cognitive capacity of the population of consumers does not seem to influence any more the performance of the environmental policies.

Results 4: With only the ecotax.

Figure 9 shows the evolution of $\bar{y}_{t}$ when only eco-tax is used on $v_{k t}, f\left(m_{k t}\right)$ and $y_{k t}$. We observe more significant results when the ecotax addresses the materiality $v_{k t}$ rather than the mobility $f\left(m_{k t}\right)$. This result is due to the already mentioned pre-existing lock-in of consumers on the mobility of the products. Finally, the lowest level of externalities is reached when the ecotax covers all sources of externalities. It is this latter case which produces the lowest level of pollution of all the 123 scenarios. This observation casts doubt on the effectiveness of information campaigns for consumers.

\section{Conclusion}

Our initial aim was twofold, firstly to ascertain whether service firms are sensitive to environmental policies and, secondly, to determine which of two policies - an eco-tax or a consumer information programme - is the more effective in fostering the emergence of an environmentally friendly dominant design in services. We have attempted to answer these questions by constructing a theoretical model of innovation in service firms. One of the particularities of this model is that it represents a process of coevolution between the dynamics of the preferences of a heterogeneous population of consumers and the direction taken by firms in their search activities. Furthermore, the firms' search space has the particularity of incorporating two major sources of pollution in service activities, namely their material environment and the mobility required by the service relationship.

Our results show that environmental policies are able to encourage service firms to introduce eco-innovations and that the ecotax policy seems to be more effective than the consumer information policy. After all, the efficacy of the 
information policy depends crucially, on one hand on the cognitive characteristics of consumers (can they easily imitate each others?), and on the other hand on the specific source of externality it aims to inhibit (is this source already taken into account by consumers as a criterion of choice, independtly of its ecological consequence?). Thus, when the imitation is easy and when the information relies upon a previously ignored service characteristic, the information policy may lead to the disappearance of niche markets in the most environmentally friendly services and encourage the emergence of a dominant design that may even be relatively more polluting than before the information policy.

For its part, the eco-tax also has a significant advantage over the information policy, namely that it causes the interests of heterogeneous groups of consumers to converge, thereby reducing the volatility of the average environmental design. Our simulations also confirm what may seem to be obvious, namely that it is better to implement public policies that focus on all the sources of pollution, in this case on the pollution caused by the materiality of services and by their mobility, rather than policies that target one or other of these sources.

\section{References}

[1] William J. Abernathy, Lim B. Clark, and Alan M. Kantrow. Industrial Renaissance, Producing a Competitive Future for America. Basic Book, 1983.

[2] Robert Ayres, Leslie Ayres, and Benjamin Warr. Is the U.S. economy dematerializing? main indicators and drivers. In Jeroen C.J.M. van den Bergh and Marco A. Janssen, editors, Economics of Industrial Ecology, chapter 3, pages 57-93. MIT Press, 2004.

[3] Richard Barras. Towards a theory of innovation in services. Research Policy, 15:161-173, 1986.

[4] William J. Baumol. The two-sided cost disease and its frightening consequences. In Faïz Gallouj and Faridah Djellal, editors, The Handbook of Innovation and Services. A Multi-disciplinary Perspective, chapter 4, pages 84-92. Edward Elgar, 2010.

[5] Simona Cantono and Gerald Silverberg. A percolation model of innovation diffusion: the relationship between diffusion, learning economies and subsidies. Technological Forecasting \&5 Social Change, 76:487-496, 2009.

[6] Fulvio Castellacci. Technological paradigms, regimes and trajectories: manufacturing and service industries in a new taxonomy of sectoral patterns of innovation. Research Policy, 37:978-994, 2008.

[7] Myong-Hun Chang and Joseph E. Harrington. Centralization vs. decentralization in a multi-unit organization: a computational model of a retail chain as a multi-agent adaptive system. Management Science, 46:14271440, 2000.

[8] Myong-Hun Chang and Joseph E. Harrington. Organization of innovation in a multi-unit firm: coordinating adaptive search on multiple rugged 
landscape. In W. Barnett et al., editor, Economic Complexity, chapter 7, pages 189-214. Emerald Group Publishing Limited, 2004.

[9] Myong-Hun Chang and Joseph E. Harrington. Agent-based models of organizations. In Leigh Tesfatsion and Kenneth L. Judd, editors, Handbook of Computational Economics. Agent-Based Computational Economics, chapter 26, pages 1273-1337. North-Holland, 2006.

[10] Erik J. de Vries. Innovation in services in networks of organizations and in the distribution of services. Research Policy, 35:1037-1051, 2006.

[11] Faridah Djellal and Faïz Gallouj. Innovation dans les services et entrepreneuriat : au-delà des conceptions industrialistes et technologistes du développement durable. Innovations, 1:59-86, 2009.

[12] European Commission Directorate-General Environment. The potential of market pull instruments for promoting innovation in environmental characteristics. Final Report, 2009.

[13] Rinaldo Evangelista. Sectoral patterns of technological change in services. Economics of Innovation and New Technology, 9:183-222, 2000.

[14] Charlotte Fourcroy, Faïz Gallouj, and Fabrice Decellas. Energy consumption in service industries: challenging the myth of non-materiality. Ecological Economics, 81:155-164, 2012.

[15] John R.P. French. A formal theory of social power. Psychological Review, 63:181-194, 1956.

[16] Noah E. Friedkin. A formal theory of social power. Journal of Mathematical Sociology, 12:103-126, 1986.

[17] Jean Gadrey. L'économie des services. La Découverte, 1992.

[18] Jean Gadrey. The environmental crisis and the economics of services: the need for revolution. In Faïz Gallouj and Faridah Djellal, editors, The Handbook of Innovation and Services. A Multi-disciplinary Perspective, chapter 5, pages 93-125. Edard Elgar, 2010.

[19] Jean Gadrey and Faïz Gallouj. Productivity, Innovation and knowledge in services. Edward Elgar, 2002.

[20] Faïz Gallouj. Economie de l'innovation dans les services. L'Harmattan, 1994.

[21] Faïz Gallouj. Les trajectoires de l'innovation dans les services : vers un enrichissement des taxonomies évolutionnistes. Economies et Sociétés, série économie et gestion des services, 1:143-169, 1999.

[22] Faïz Gallouj. Innovation in the service economy : the new wealth of nations. Edward Elgar, 2002.

[23] Faïz Gallouj and Faridah Djellal. The Handbook of Innovation and Services. A multidisciplinary perspective. Edward Elgar, 2010.

[24] Faïz Gallouj and Faridah Djellal. Introduction: filling the innovation gap in the service economy - a multidisciplinary perspective. In Faïz Gallouj and Faridah Djellal, editors, The Handbook of Innovation and Services. A Multi-disciplinary Perspective, chapter Introduction, pages 1-23. Edward Elgar, 2010. 
[25] Faïz Gallouj and Maria Savona. Innovation in services: a review of the debate and a research agenda. Jouranl of Evolutionary Economics, 19:149172, 2009.

[26] Faïz Gallouj and Olivier Weinstein. Innovation in services. Research Policy, 26:537-556, 1997.

[27] Rainer Hegselmann and Andreas Flache. Understanding complex social dynamics: a plea for cellular automata based modeling. Journal of Artificial Societies and Social Simulation, 1:http://jasss.soc.surrey.ac.uk/1/3/1.html, 1998.

[28] Rainer Hegselmann and Ulrich Krause. Opinion dynamics and bounded confidence. models, analysis and simulation. Journal of Artificial Societies and Social Simulation, 5:http://jasss.soc.surrey.ac.uk/5/3/2.html, 2002 .

[29] Rainer Hegselmann and Ulrich Krause. Opinion dynamics driven by various ways of averaging. Computational Economics, 25:381-405, 2005.

[30] Peter Hill. On goods and services. Review of Income and Wealth, 23:315338, 1977.

[31] Christian Hipp and Hariolf Grupp. Innovation in the service sector: the demand for service-specific innovation measurement concepts and typologies. Research Policy, 34:517-535, 2005.

[32] John H. Holland. Adaptation in Natural and Artificial Systems. MIT Press, 1992.

[33] Jeremy Howells. Services and innovation: conceptual and theoretical perspectives. In J. R. Bryson and P. W. Daniels, editors, The Handbook of Service Industries, pages 34-44. Edward Elgar, 2007.

[34] Marco A. Janssen and Wander Jager. An integrated approach to simulating behavioral processes: a case study of the lock-in of consumption patterns. Journal of Artificial Societies and Social Simulation, 2:http://jasss.soc.surrey.ac.uk/2/2/2.html, 1999.

[35] Marco A. Janssen and Wander Jager. Fashions, habits and changing preferences: simulation of psychological factors affecting market dynamics. Journal of Economic Psychology, 22:745-772, 2001.

[36] Marco A. Janssen and Wander Jager. Stimulating diffusion of green products. co-evolution between firms and consumers. Journal of Evolutionary Economics, 12:2383-306, 2002.

[37] Stuart Kauffman. The Origins of Order. Self Organization and Selection in Evolution. Oxford University Press, 1993.

[38] Stuart Kauffman. At Home in the Universe. Oxford University Press, 1995.

[39] Stuart Kauffman, José Lobo, and William G. Macready. Optimal search on a technolgy landscape. Journal of Economic Behavior $\& 3$ Organization, 43:141-166, 2000.

[40] Steven Kleper. Entry, exit, and innovation over the product life cycle. The American Economic Review, 86:562-583, 1996. 
[41] Stephen J. Kline and Nathan Rosenberg. An overview of innovation. In Ralph Landau and Nathan Rosenberg, editors, The Positive Sum Strategy. Harnessing Technology for Economic Growth, chapter 16, pages 175306. The National Academy of Sciences, 1986.

[42] Kelvin J. Lancaster. A new approach to consumer theory. Journal of Political Economy, 74:132-157, 1966.

[43] Daniel A. Levinthal. Adaptation on rugged landscapes. Management Science, 43:934-950, 1997.

[44] Hein Mannaerts. Environmental policy analysis with stream: a partial equilibrium model for material flows in the economy. In Jeroen C.J.M. van den Bergh and Marco A. Janssen, editors, Economics of Industrial Ecology, chapter 7, pages 195-222. MIT Press, 2004.

[45] James G. March. Exploration and exploitation in organizational learning. Organization Science, 2:71-87, 1991.

[46] Ian Miles. Service innovation: Towards a tertiarisation of innovation studies. In Jean Gadrey and Faallouj, editors, Productivity, Innovation and Knowledge in Services, chapter 8, pages 164-196. Edward Elgar, 2002 .

[47] Richard R. Nelson and Davide Consoli. An evolutionary theory of household consumption behavior. Journal of Evolutionary Economics, 20:665687,2010 .

[48] OECD. The service economy, 2000.

[49] Keith Pavitt. Sectoral patterns of technical change: towards a taxonomy and a theory. research Policy, 13:343-373, 1984.

[50] Everett M. Rogers. Diffusion of innovations. The Free Press, 1995.

[51] Pier Paolo Saviotti and John Stanley Metcalfe. A theoratical approach to the construction of technological output indicators. Research Policy, 13:141-151, 1984.

[52] Bruce S. Tether. Do services innovate (differently)?: Insights from the european innobarometer survey. Industry and Innovation, 12:153-184, 2005.

[53] Paul Windrum and Manuel Garcia-Go ni. A neo-schumpeterian model of health services innovation. Research Policy, 37:649-672, 2008.

[54] Ulrich Witt. Learning to consume-a theory of wants and the growth of demand. Journal of Evolutionary Economics, 11:23-36, 2001.

[55] Sewall Wright. Evolution in mendelian populations. Bultin of Mathematical Biology, reprinted from Genetics (vol. 16, 1931), 52:241-295, 1990. 
Figure 1: Extreme cases of a covariant and a totally random fitness landscape (Chang and Harrington, 2006 p.1291)
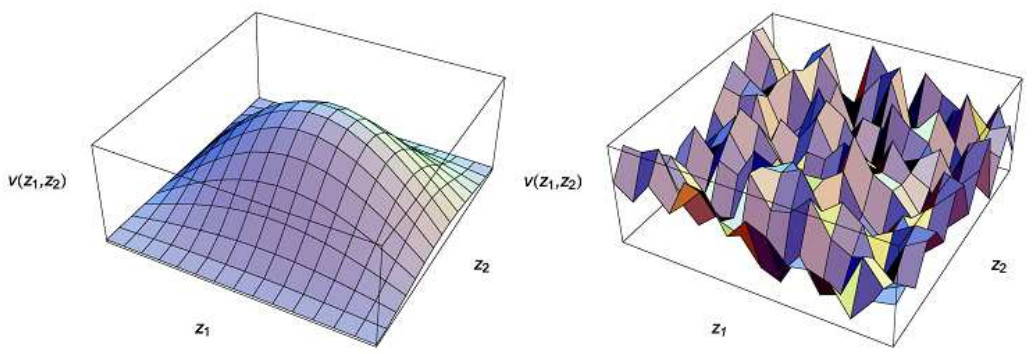

Figure 2: Von Neumann neighborhood
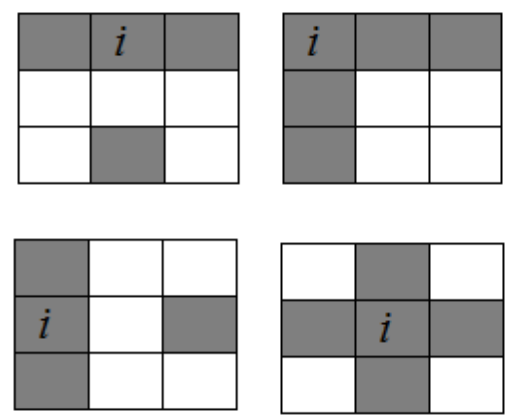

Figure 3: Summary of the general functioning of the model

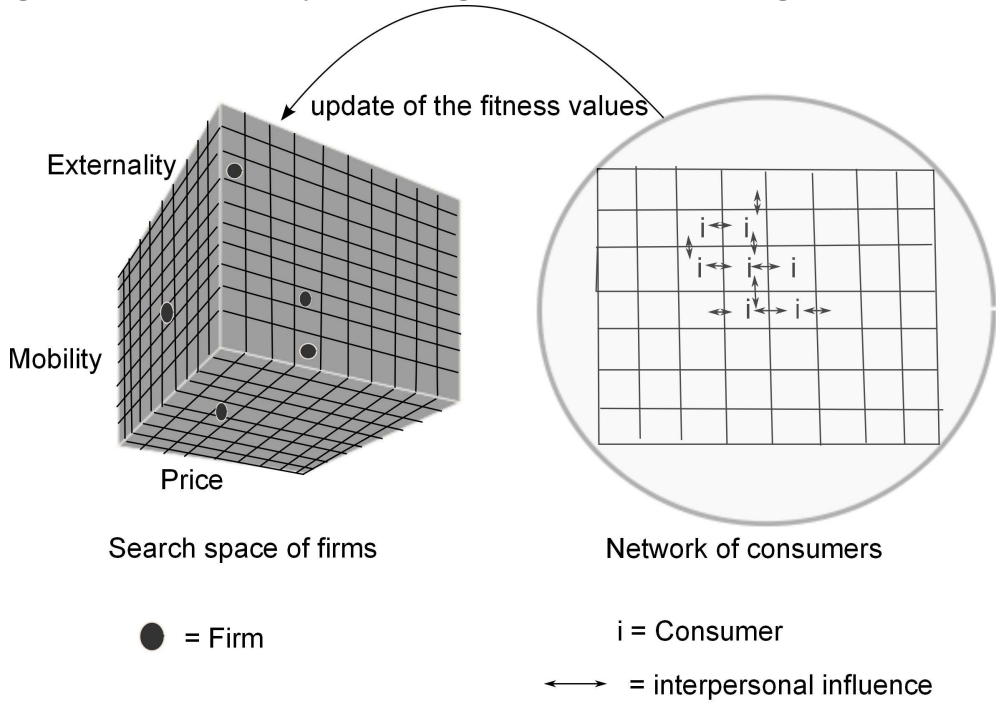

Table 1: Search heuristic of a firm $k$ if $\left(M S_{k t} \leq M S_{t}\right)$

Observes each one of the 6 possibilities of incremental innovations offered by the immediate neighborhood. Stores their fitness values.

Randomly chooses a design from the $10^{3}$ possibile designs.

Stores its fitness value.

Compares the fitness of the stored designs

Moves up to the most efficient design 
Figure 4: Evolution of the performance achieved by companies on the simulated market

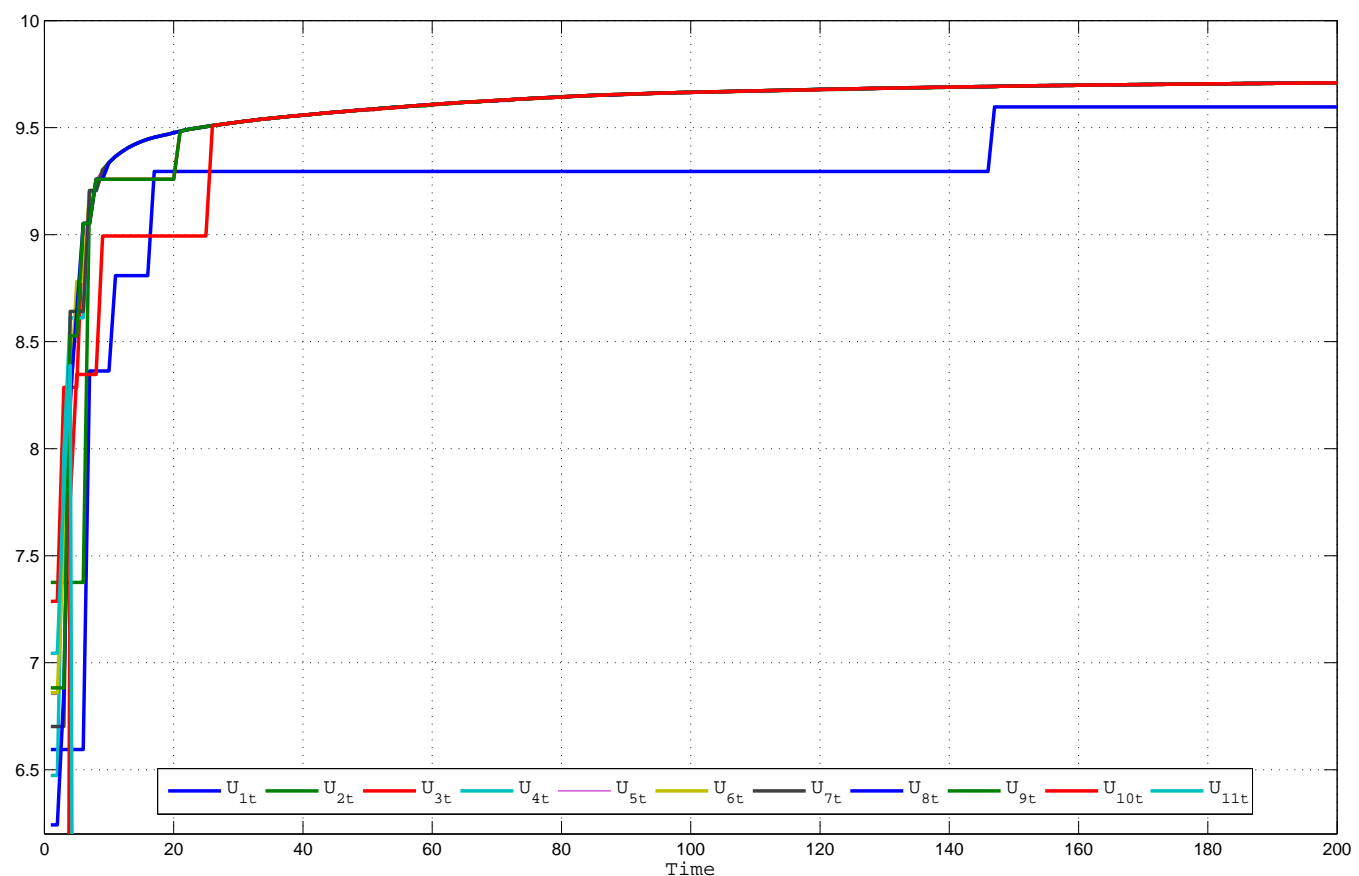

Figure 5: Evolution of the designs of the $k$ products in terms of prices.

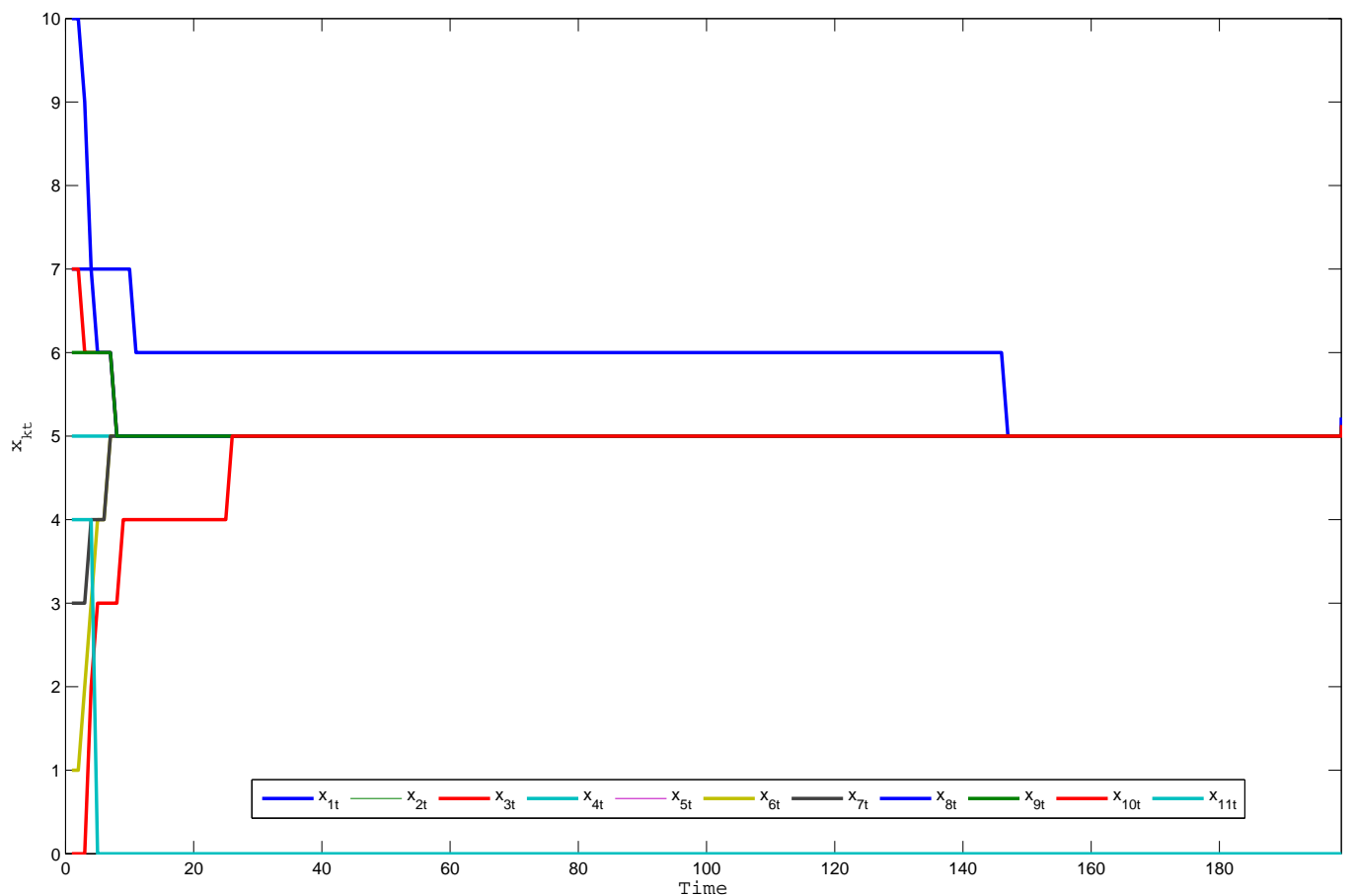




\begin{tabular}{|c|c|}
\hline & Price $x_{k t}$ \\
\hline Without tax, $T=0$ & $x_{k t} \in[1 ; 10]$ \\
\hline$T=v_{k t}$ & $x_{k t} \in[2 ; 20]$ \\
\hline$T=f\left(m_{k t}\right)$ & $x_{k t} \in[2 ; 20]$ \\
\hline$T=y_{k t}$ & $x_{k t} \in[3 ; 30]$ \\
\hline
\end{tabular}

Table 2: Effect of different tax policies on the price scale

Table 3: Summary of the simulated scenarios for each of the 3 levels of Government information

\begin{tabular}{|c|c|c|c|c|c|c|c|c|c|}
\hline \multicolumn{5}{|c|}{ Information policy } & \multicolumn{4}{|c|}{ information and eco-tax } & \multirow{2}{*}{ eco-tax } \\
\hline & $\mathrm{K}=0$ & $\mathrm{~K}=1$ & $\mathrm{~K}=2$ & $\mathrm{~K}=3$ & $\bar{K}=0$ & $\mathrm{~K}=1$ & $\mathrm{~K}=2$ & $\mathrm{~K}=3$ & \\
\hline $\mathrm{E}=1$ & & & & & & & & & \\
\hline $\mathrm{E}=2$ & & & & & & & & & \\
\hline $\mathrm{E}=5$ & & & & & & & & & \\
\hline $\mathrm{E}=7$ & & & & & & & & & \\
\hline $\mathrm{E}=10$ & & & & & & & & & \\
\hline
\end{tabular}




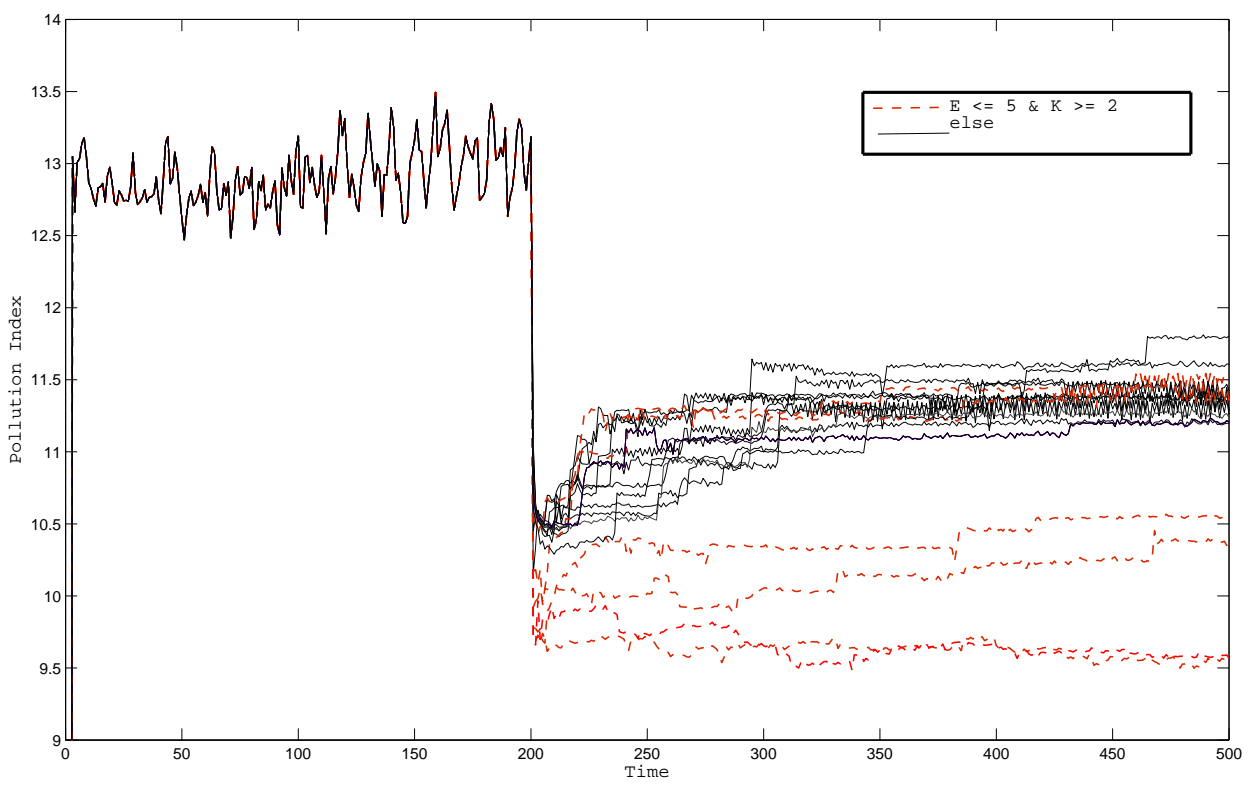

(a)

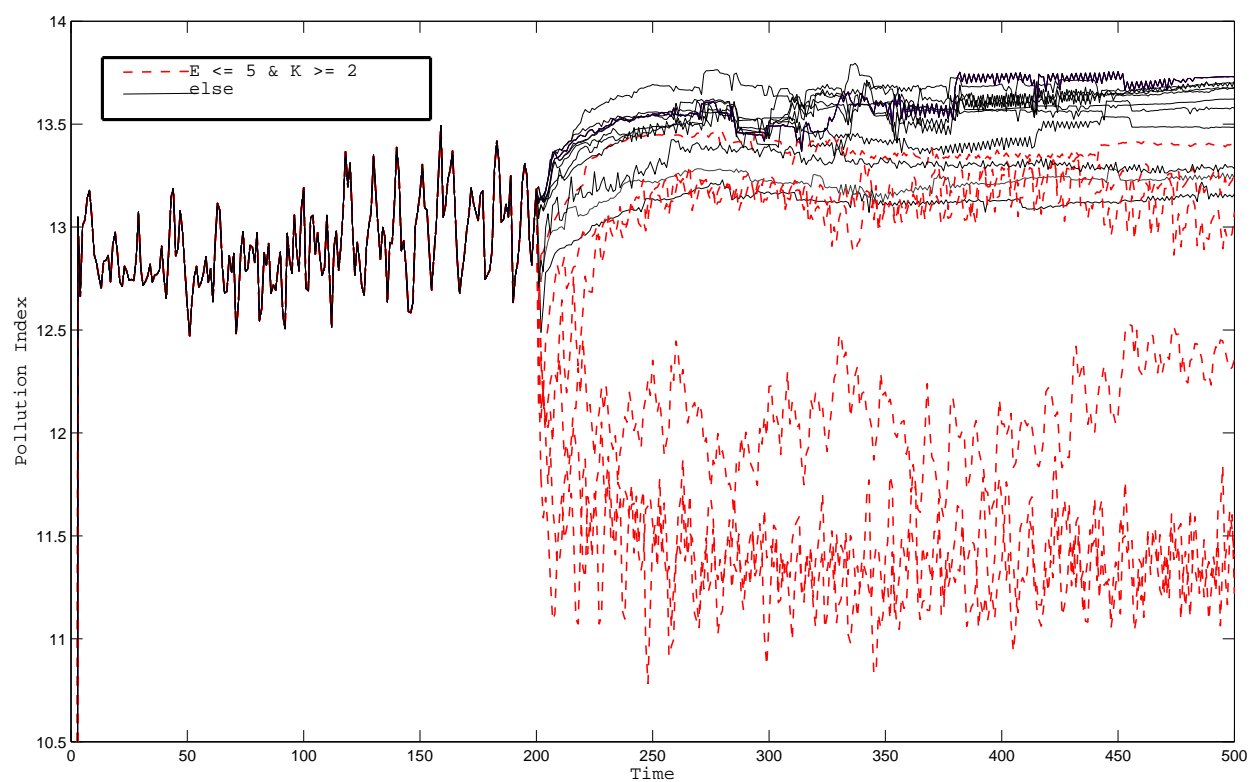

Figure 6: Evolution of the pollution index $\bar{y}_{t}$ (a) with ecotax and information policy applied to the externality produced by materiality $v_{k t}$, (b) with only information policy. 


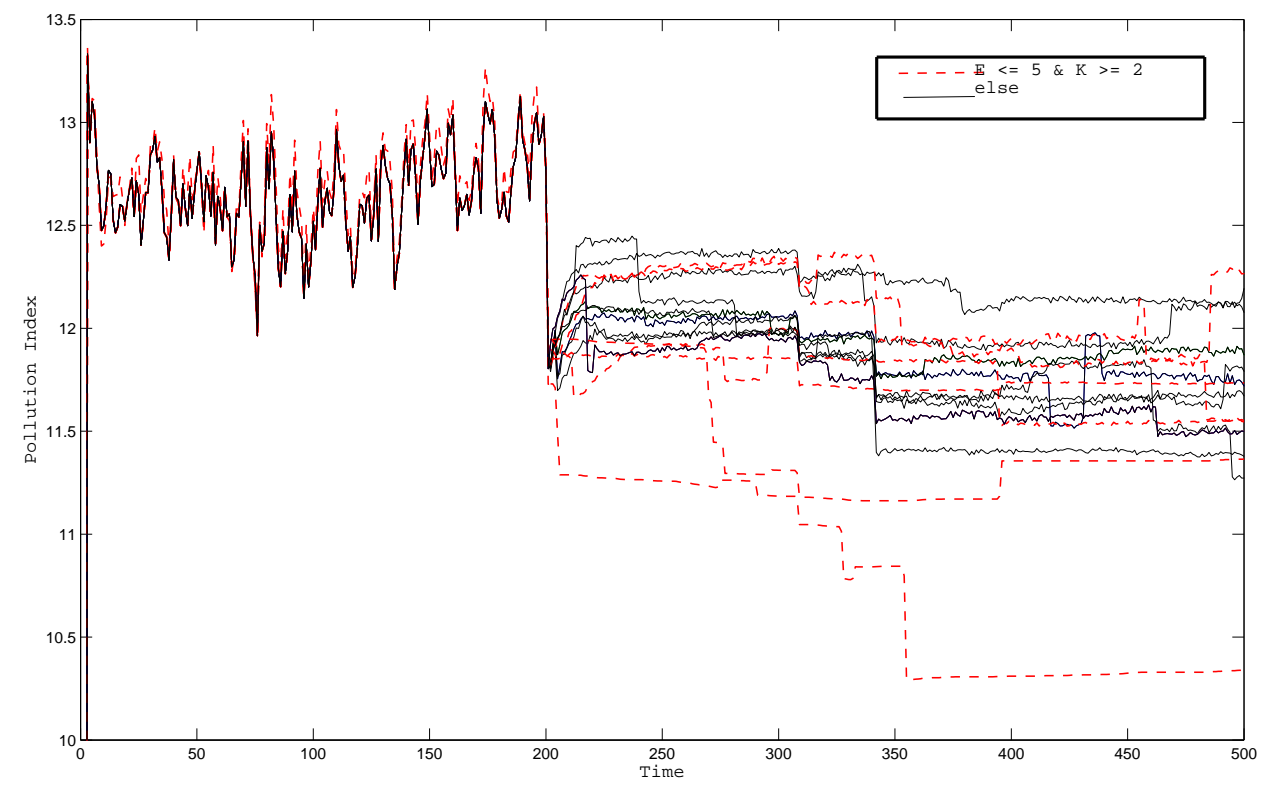

(a)

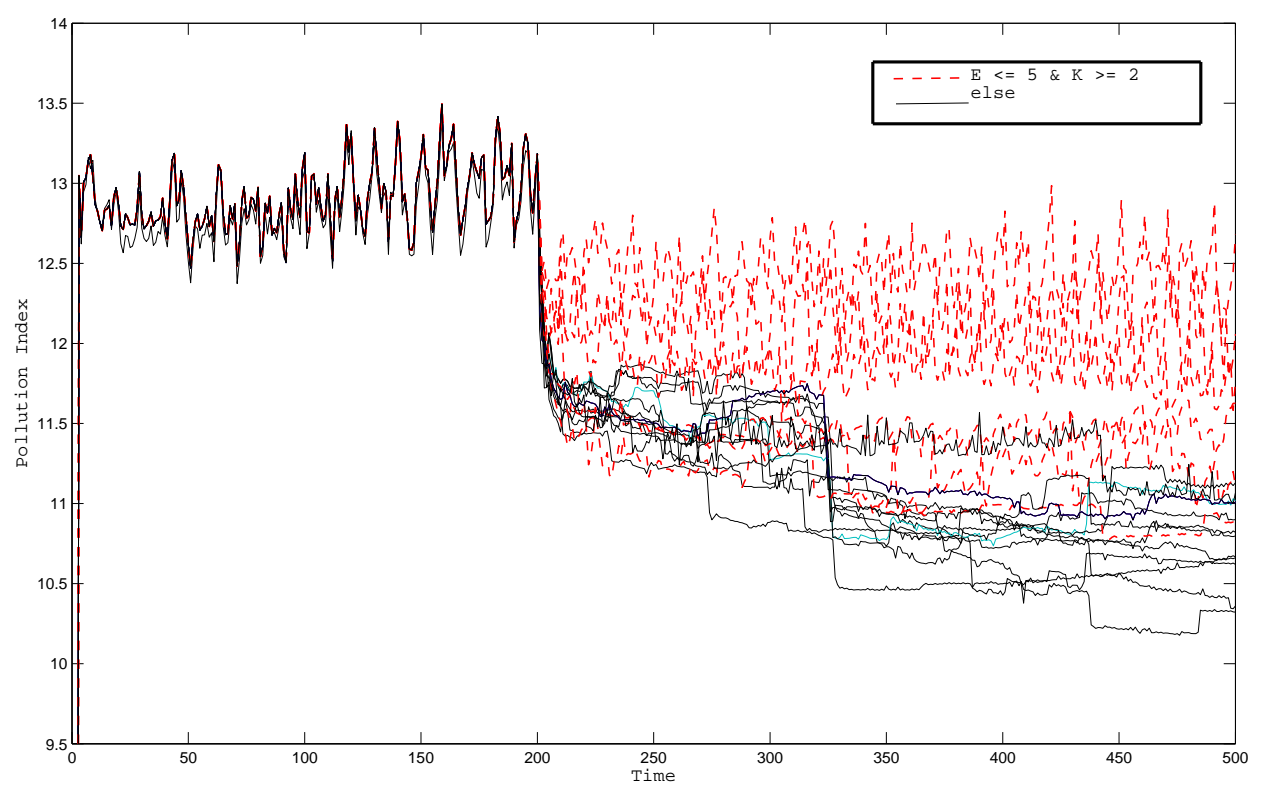

Figure 7: Evolution of the pollution index $\bar{y}_{t}$ (a) with ecotax and information policy applied to the externality produced by mobility $f\left(m_{k t}\right)$, (b) with only information policy. 


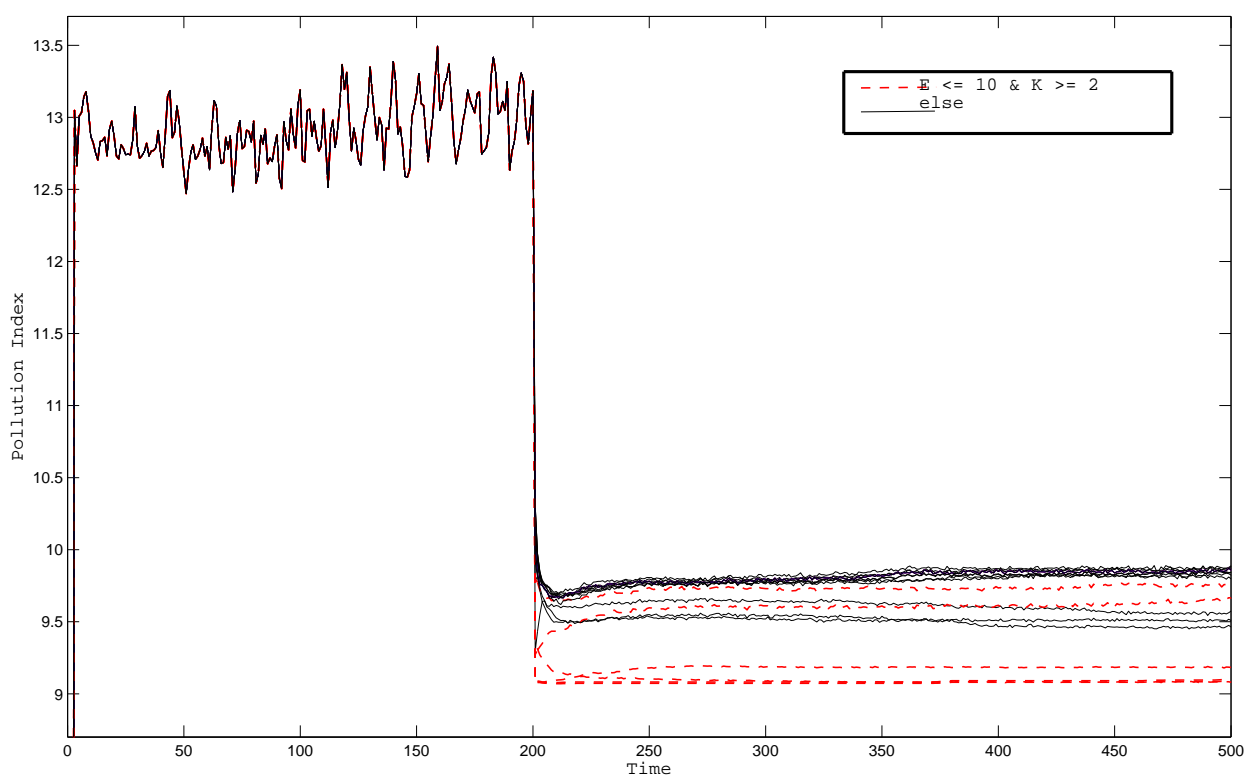

(a)

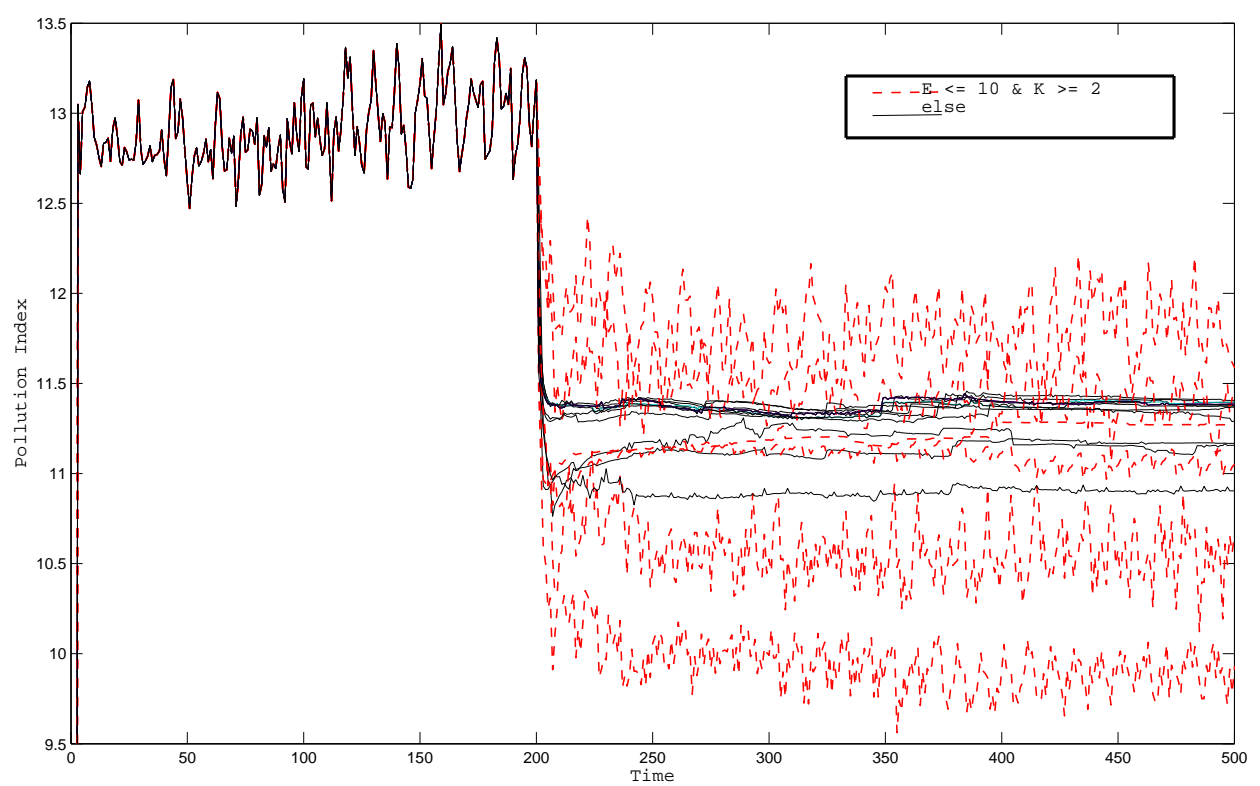

Figure 8: Evolution of the pollution index $\bar{y}_{t}$ (a) with ecotax and information policy applied to all the sources of externality $y_{k t}=v_{k t}+f\left(m_{k t}\right)$, (b) with only information policy. 


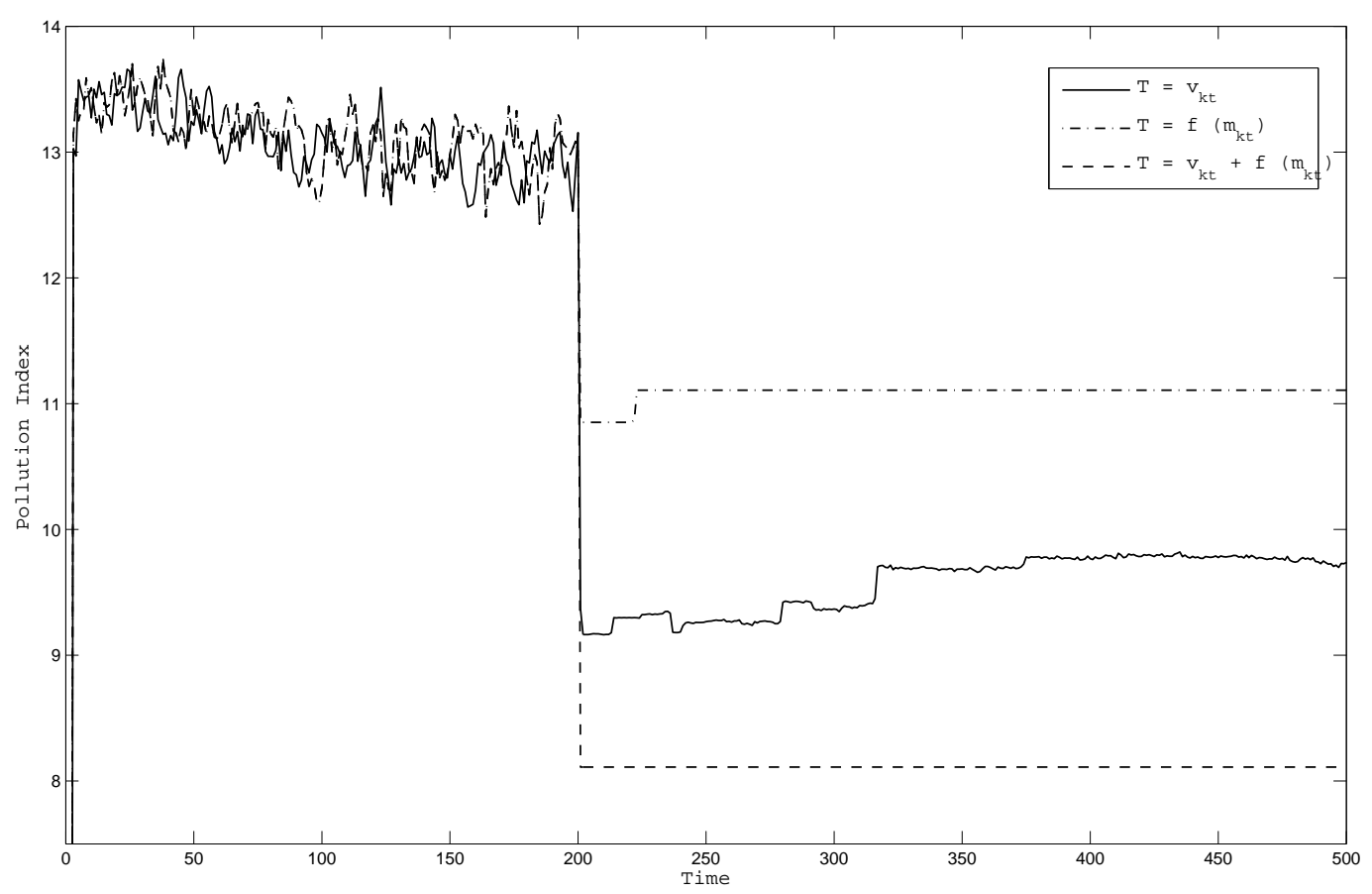

Figure 9: Evolution of the pollution index $\bar{y}_{t}$ with only ecotax applied to the externality coming from materiality $v_{k t}$, from mobility $f\left(m_{k t}\right)$ and to all the sources of externality $y_{k t}=v_{k t}+f\left(m_{k t}\right)$. 